\title{
Observational clinical human reliability analysis (OCHRA) for assessing and improving quality of surgical performance: the current status and future
}

\section{Benjie Tang*}

Surgical Skills Centre, Dundee Institute for Healthcare Simulation, Ninewells Hospital and Medical School, University of Dundee, Dundee, UK

${ }^{*}$ Corresponding author at: Surgical Skills Centre, Dundee Institute for Healthcare Simulation, Ninewells Hospital and Medical School, University of Dundee, Dundee, UK. Email: b.tang@dundee.ac.uk

Date accepted for publication: 8 June 2020

\section{Abstract}

Morbidity and mortality data (MMD), as the traditional measure of surgical performance, have major limitations when used to assess and ensure quality of surgical performance. To improve and ensure the safest possible surgical performance, there is a need for prospective observational multidisciplinary studies, for which surgeons and human factor specialists should work together towards this objective. These considerations have led to the development of new systematic approaches for assessing and improving surgical operative performance. One of these is human reliability analysis (HRA), which eventually progressed to observational clinical human reliability analysis (OCHRA). HRA techniques are widely used in the risk management of safety-critical systems, e.g. nuclear power industry, aviation industry, and military operations. HRA techniques determine the impact of human error within a system. Surgical complications are related to techniques and result from errors most commonly committed during the intervention. Therefore, these errors can be influenced, i.e. deducted, by an HRA system that proactively reduces risk by preventing errors during human activities to the 'as low as reasonably possible'. Two major limitations of OCHRA are its labour-intensive nature and the requirement for human factors engineering expertise in the assessment. These issues will be resolved in the short term by the significant progress based on artificial intelligence and machine learning, alongside with increased clinical use of OCHRA in surgical practice and health care in general.

Keywords: patient safety; surgical performance; medical error; human error; simulation-based training; observational clinical human reliability analysis (OCHRA)

\section{Introduction}

Surgery has advanced significantly over the last 40 years. A pertinent example is the remarkable evolution of the development and use of minimal access surgery and robotic surgery. ${ }^{1,2}$ New procedures are continuously being developed and performed for enhanced patient benefit and improved health care systems. Moreover, new approaches involve use of new techniques and technologies such as transanal total mesorectal excision using robotic-assisted laparoscopic surgery. ${ }^{3}$ Because of these changes, these developments inevitably lead to added complexity and increased difficulty of execution. New complications associated with new procedures are directly related to suboptimal technique and resulting errors most commonly committed during the intervention, which were not enacted beforehand. ${ }^{4,5}$ Inevitably, there is always a proficiency-gain curve associated with performing a new procedure using a surgical approach or technology. ${ }^{6}$

According to a recent study, more than 250,000 people in the United States die every year from medical errors, making it the third leading cause of death after heart disease and cancer. ${ }^{7}$ Surgery contributes to $48 \%$ of all adverse events and to $13 \%$ of all hospital deaths. ${ }^{8}$ Surgeons have been identified as a risk factor that contributes to surgical errors that lead to morbidity and mortality. ${ }^{9,10}$ Morbidity and mortality data (MMD) are traditionally used to assess the quality of surgery. ${ }^{11}$ However, MMD have not enabled surgeons to prevent or reduce surgical errors. Hence, there 
is an unmet need for urgent development of new tools and approaches to objectively assess and improve surgical performance in both clinical practice and surgical training.

\section{Limitations of MMD and the way forward}

The approaches developed and applied to measure and ensure the quality of surgical performance have become crucial in determining patient outcomes after surgery. However, MMD, as the traditional measure of surgical performance, have major limitations when used to assess and ensure quality of surgical performance. First, they do not identify factors, such as errors enacted during the preoperative, intra-operative and postoperative periods, which are responsible for specific complications. Second, MMD do not correlate specific complications with technical errors. This information is crucial for improving surgical performance $^{12}$ as patient outcomes of surgery are mostly surgeon related. In this respect, surgeons have been identified as a risk factor in patient safety. ${ }^{10}$ Third, there are several other factors associated with surgeons' competence that have an impact on patients' postoperative outcomes, such as nontechnical skills. ${ }^{13}$ Fourth, the main disadvantage of MMD is its retrospective nature, such that the problem(s) are identified during audit and hence unfavourable clinical outcomes are not prevented and continue to accumulate, even when the audit is in progress. MMD only partially provide key information on learning opportunities to prevent or reduce the risk of future adverse events. ${ }^{12}$ Therefore, to improve and ensure the safest possible surgical performance, there is a need for prospective observational multidisciplinary studies, and surgeons and human factor specialists should work together towards this objective. ${ }^{12}$ These considerations have led to the development of new systematic approaches for assessing and improving surgical operative performance. One of these is human reliability analysis (HRA), which eventually progressed to observational clinical human reliability analysis (OCHRA). ${ }^{14}$

\section{HRA and OCHRA}

HRA techniques are widely used in risk management of safety-critical systems, e.g. the nuclear power industry, the aviation industry, and military operations. ${ }^{15}$ HRA techniques determine the impact of human error within a system. The techniques involved are mainly those of systems for engineering, cognitive and behavioural science to analyse, evaluate, and understand the human contribution to a system's reliability and safety. Common steps of the HRA process consist of problem definition and specification of the plan for the task analysis, task modelling, human error identification and analysis, human error quantification, and error management recommendations. ${ }^{15,16}$ If surgery is regarded as one of the high-risk specialities, surgical complications are related to techniques and result from errors most commonly committed during the intervention. Therefore, these errors can be influenced, i.e. deducted, by an HRA system that proactively reduces risk by preventing errors during human activities to the 'as low as reasonably possible' (ALARP region). ${ }^{12}$

OCHRA was developed 20 years ago at the Surgical Skills Unit (SSU) within the Department of Surgery and Molecular Oncology some 2 years after the first laparoscopic cholecystectomy in the UK was performed by Professor Sir Alfred Cuschieri in May 1987 at Ninewells Hospital and Medical School, University of Dundee, UK. The idea of OCHRA originated from Professor Cuschieri. ${ }^{17}$ Dr Tang did the original research in translating HRA to OCHRA for his doctoral thesis some 20 years ago and is an expert in human factors. ${ }^{14}$ The SSU was established by Professor Sir Alfred Cuschieri with funds donated by Lord Wolfson and matched funding by the Department of Health and Social Security. It was the first laboratory of its kind in the UK and Europe and is now called the Cuschieri Skills Centre. Its primary remit was to train surgeons in the safe conduct of laparoscopic surgery to avoid the spate of operative iatrogenic injuries, including deaths on the table witnessed between 1988 and 1990. SSU was awarded the Queen's award for higher and continued education in 1999.

\section{The advantages and future of OCHRA}

OCHRA and related studies have been presented at major international surgical meetings, including congresses of the European Association of Endoscopic Surgeons, the Society of American Gastrointestinal Endoscopic Surgeons, Association of Surgeons of Great Britain and Ireland, Society of Academic and Research Surgery, and the American College of Surgeons. One significant advantage of error classification is the insight it provides into the nature of error itself, which clarifies its root cause, i.e. why it occurred. This is fundamentally important for improving both patient safety in clinical practice and surgical training by error analysis. ${ }^{6,14,18}$ We have advocated that the proficiency-gain curve and surgical errors should be transferred from operating theatres and patients into surgical skills training labs and onto simulators. A wide range of simulation-based surgical training approaches have been developed and applied in surgical training curricula based on evidence. ${ }^{19}$

Despite the benefit of human error analysis and its role in the causation of adverse events, human error classification 
has not been included in the International Patient Safety Classification conceptual framework, ${ }^{20}$ presumably because HRA techniques have been infrequently used in health care practice. Despite being the only method of providing objective assessment of performance of an operation by any surgeon, its uptake as confirmed by a systemic review, ${ }^{21}$ has been disappointing. Hence, the benefits of OCHRA in improving both surgical training of residents and surgical performance by established specialist consultant/attending surgeons will only materialize fully with increased usage. In addition, the benefit of OCHRA for optimizing patient safety is contingent on continued research and development of the technique to overcome its current limitations. Two major limitations of OCHRA are its labour-intensive nature and the requirement for human factors engineering expertise in the assessment. However, these issues will be resolved in the short term by the significant progress based on artificial intelligence and machine learning, ${ }^{22}$ alongside increased clinical use of OCHRA in surgical practice and health care in general. ${ }^{23}$

\section{Conflict of interest}

No financial or personal conflicts of interest declared.

\section{References}

1. Cuschieri A, Dubois F, Mouiel J, Mouret P, Becker H, Buess G, et al. The European experience with laparoscopic cholecystectomy. Am J Surg 1991; 161(3): 385-387. https://doi.org/10. 1016/0002-9610(91)90603-B.

2. Tan A, Ashrafian H, Scott AJ, Mason SE, Harling L, Athanasiou $\mathrm{T}$, et al. Robotic surgery: disruptive innovation or unfulfilled promise? A systematic review and meta-analysis of the first 30 years. Surg Endosc 2016; 30(10): 4330-4352. https://doi.org/10.1007/s00464-016-4752-x.

3. Carmichael H, D'Andrea AP, Skancke M, Obias V, Sylla P. Feasibility of transanal total mesorectal excision (taTME) using the Medrobotics Flex ${ }^{\circledR}$ System. Surg Endosc 2020; 34(1): 485-491. https://doi.org/10.1007/s00464-019-07019-y.

4. The Southern Surgeons Club. A prospective analysis of 1518 laparoscopic cholecystectomies. N Engl J Med 1991; 324(16): 1073-1078. https://doi.org/10.1056/NEJM199104183241601.

5. Way LW, Stewart L, Walter W, Liu K, Lee CM, Whang K, et al. Causes and prevention of laparoscopic bile duct injuries: analysis of 252 cases from a human factors and cognitive psychology perspective. Ann Surg 2003; 237 (4): 460-469. https://doi.org/10.1097/01.SLA.0000060680.92690.E9.

6. Talebpour M, Alijani A, Hanna GB, Moosa Z, Tang B, Cuschieri A. Proficiency-gain curve for an advanced laparoscopic procedure defined by observation clinical human reliability assessment (OCHRA). Surg Endosc 2009; 23(4), 869-875. https://doi.org/10.1007/s00464-008-0088-5.

7. Brennan TA, Leape LL, Laird NM, Hebert L, Localio AR, Lawthers AG, et al. Incidence of adverse events and negligence in hospitalized patients. Results of the Harvard Medical Practice Study I. N Engl J Med 1991; 324(6): 370-376. https://doi.org/10.1056/NEJM199102073240604.

8. Makary MA, Daniel M. Medical error-the third leading cause of death in the USA. BMJ 2016; 353: https://doi.org/10. 1136/bmj.i2139.

9. Porter GA, Soskolne CL, Yakimets WW, Newman SC. Surgeon-related factors and outcome in rectal cancer. Ann Surg 1998; 227(2): 157-167. https://doi.org/10. 1097/00000658-199802000-00001.

10. COLOR Study Group. Impact of hospital case volume on short-term outcome after laparoscopic operation for colonic cancer. Surg Endosc 2005; 19(5): 687-692. https://doi.org/10. 1007/s00464-004-8920-z.

11. Campbell WB. Surgical morbidity and mortality meetings. Ann R Coll Surg Engl 1988; 70: 363-365. PMID: 3207327.

12. Cuschieri A. Nature of human error: implications for surgical practice. Ann Surg 2006; 244(5): 642-648. https://doi.org/10. 1097/01.sla.0000243601.36582.18.

13. Ounounou E, Aydin A, Brunckhorst O, Khan S, Dasgupta P, Ahmed K. Nontechnical skills in surgery: a systematic review of current training modalities. J Surg Educ 2018; 76: 14-24. https://doi.org/10.1016/j.jsurg.2018.05.017.

14. Tang B, Hanna GB, Joice P, Cuschieri A. Identification and categorization of technical errors by observational clinical human reliability assessment (OCHRA) during laparoscopic cholecystectomy. Arch Surg 2004; 139; 1215-1220. https://doi.org/10.1001/archsurg.139.11.1215.

15. Chandler F, Chang Y, Moslech A, Marble J, Boring R, Gertman D. Human reliability analysis methods: selection guidance for NASA. Washington, DC: NASA; 2006. NASA/Office of Safety and Mission Assurance Technical Report.

16. Cuschieri A, Tang B. Human reliability analysis (HRA) techniques and observational clinical HRA. Minim Invasive Ther Allied Technol 2010; 19(1); 12-17. https://doi.org/10. 3109/13645700903492944.

17. Joice P, Hanna GB, Cuschieri A. Errors enacted during endoscopic surgery: a human reliability analysis. Appl Ergon 1998; 29(6): 409-414. https://doi.org/10.1016/S0003-6870(98) 00016-7.

18. Ghazanfar MA, Cook M, Tang B, Tait I, Alijani A. The effect of divided attention on novices and experts in laparoscopic task performance. Surg Endosc 2015; 29(3): 614-619. https://doi.org/10.1007/s00464-014-3708-2.

19. Tang B, Zhang L, Alijani A. Evidence to support the early introduction of laparoscopic suturing skills into the surgical training curriculum. BMC Med Educ 2020; 20(1): 70. https://doi.org/10.1186/s12909-020-1986-z. 
20. World Health Organization. International Patient Safety Classification conceptual framework. Geneva: WHO; 2009. Available from: https://www.who.int/patientsafety/taxonomy/ icps_full_report.pdf?ua $=1$.

21. Tang B, Cuschieri A. Objective assessment of surgical operative performance by observational clinical human reliability analysis (OCHRA): a systematic review. Surg Endosc 2020; 34(4): 1492-1508. https://doi.org/10.1007/s00464-019-07365-x.
22. Hashimoto DA, Rosman G, Rus D, Meireles OR. Artificial intelligence in surgery: promises and perils. Ann Surg 2018; 268(1): 70-76. https://doi.org/10.1097/SLA.000000 0000002693.

23. Sujan MA, Embery D, Huang H. On the application of human reliability analysis in healthcare: Opportunity and challenges. Reliab Eng Syst Saf 2020; 194:106189 https://doi.org/10.1016/j. ress.2018.06.017. 